\title{
Cognitive Style of Humanities, Commerce and Science Students - A Study on Higher Secondary Students from West Bengal
}

\author{
Sukrita Mukherjee $^{1}$, Dr. Ishita Chatterjee ${ }^{2}$
}

\section{ABSTRACT}

Cognitive style or thinking style is a term used in cognitive psychology to describe the way individuals think, perceive and remember information. The present study aims to understand the cognitive style adapted by higher secondary students. The study sample consists of 90 higher secondary school students (30 each from science, humanities and commerce background). The male female ratio was 50:50. The age range was from 16-18 years. They were all from middle socio-economic status. They were administered an adapted version of cognitive style questionnaire by Ancona, Kochan, Scully, Van maanen and Westney. The results indicate for the dimension of Sensing there was significant effect of stream of study and gender. For the Intuition dimension again there was a significant effect of stream and gender. For Perceiving dimension also there was a significant effect of stream and gender. Sensing was highest for the science stream and lowest for the Humanities. Again Intuition was highest for the Humanities stream and lowest for the Science stream. The males have always scored highest in the dimension of Perceiving than their female counterparts both in Humanities and Science stream. And the female irrespective of the stream of study has scored higher in the Intuitive dimension.

The present study is helpful in the field of designing educational guidance and curriculum for the Higher Secondary Students.

Keywords: Students, Cognitive style, Course of study.

Cognitive style is considered as one of the most important variable affecting the students in academics. Cognitive style is described as the way individuals imagine, perceive, distinguish, recognise, think and remember information. It is a persisting habitual pattern of perceptual and intellectual activity (Rishipal, 2012). With the help of cognitive styles an individual acquires knowledge (cognition) and processes information (conceptualisation) (Kirton, 2003).

\footnotetext{
${ }^{1}$ M.A In Applied Psychology, University of Calcutta, India

${ }^{2}$ Assistant Professor, Dept. Of Applied Psychology, University of Calcutta, India

*Responding Author

(C) 2016 I S Mukherjee, I Chatterjee; licensee IJIP. This is an Open Access Research distributed under the terms of the Creative Commons Attribution License (http://creativecommons.org/licenses/by/2.0), which permits unrestricted use, distribution, and reproduction in any Medium, provided the original work is properly cited.
} 


\section{Cognitive Style of Humanities, Commerce and Science Students - A Study On Higher Secondary Students from West Bengal}

Ellis (2000) said the characteristic cognitive, affective and physiological behaviours serve as relatively stable indicators of how learners perceive, interact with and respond to the learning environment. Cognitive style is viewed as bipolar meaning that learners can be found on a continuum of two opposing characteristics (Grossmann, 2011). The cognition centred approach focussed on individual differences in cognition and perception, and as a result the researchers identified several styles, abilities and dimensions of cognitive processing (Cano Garcia, Francisco, Hughes, and Elaine, 2000). Cognitive and constructivist theorists have considered learning and instruction related to individual differences (Kiraz, Cagiltay, Cakiroglu, and Karaaslan 2005). Optimum learning depends on a variety of factors like past learning, stage of development, nature of material and individual differences. So, individualised learning is strongly associated with the characteristics of the learner, his or her cognitive style. Cognitive style has been identified as one of the most pertinent factors that affect students' learning preference (Chen and Liu, 2009).

Cognitive style remains a key concept in the areas of education and management. If a pupil has a cognitive style that is similar to that of his/her teacher, the chances that the pupil will have a more positive learning experience are improved. Likewise, team members with similar cognitive styles likely feel more positive about their participation with the team. While matching cognitive styles may make participants feel more comfortable when working with one another, this alone cannot guarantee the success of the outcome.

Personality is the sum total of the behavioural and mental characteristics that are distinctive of an individual (Colamn, 2009,). It refers to individuals' unique and relatively stable patterns of behaviour, thoughts and feelings (Baron, 2006,). The theory of person-situation interaction predicts that the extrovert will adapt best when he is asked to collaborate with others and that the introvert will adapt best when she is asked to carry out tasks independently (Santrock, 2006,). Extroverted individuals are outgoing, sociable and assertive; introverts are quiet and shy (Robbins, 2005). In a study it was found that the development of social norms among different personality groups and found that introvert females showed better retention in reasoning concepts than their counterpart i.e. male and extrovert.

The dominant view in the field of personality psychology today holds that personality emerges early and continues to change in meaningful ways throughout the lifespan. Evidence from largescale, long-term studies has supported this perspective.

In the present study 8 dimensions of cognitive styles have been taken into consideration and has been applied to Higher Secondary students(belonging to Humanities, Commerce and Science group respectively)by using The Cognitive style questionnaire by Ancona, Kochan, Scully, Van Maanen, and Westney (1997), and the dimensions are; Introversion, Extraversion, Sensing, Intuitive, Thinking, Feeling, Judging, and Perceiving respectively. 


\section{Cognitive Style of Humanities, Commerce and Science Students - A Study On Higher Secondary Students from West Bengal}

Introversion: Introversion is one of the major personality traits identified in many theories of personality. Introversion is generally viewed as existing as part of a continuum along with extraversion.

Common Introversion Traits: Very self-aware, Thoughtful, Enjoys understanding details, Interested in self-knowledge and self-understanding, Tends to keep emotions private.

Extraversion: People who are high in extraversion tend to seek out social stimulation and opportunities to engage with others. These individuals are often described as being full of life, energy and positivity.

Common Extraversion Traits: Warmth, Seeking novelty and excitement, Gregariousness, Assertive, Cheerful, Talkative, Enjoys being the centre of attention, Action oriented.

Sensing: Sensing is an ability to deal with information on the basis of its physical qualities and its affection by other information. Sensing refers to how people process data. Sensing people focus on the present, they are "here and now" people, who are factual and process information through the five senses. They see things as they are, they are concrete thinkers.

Common sensing traits: Concrete, Realistic, Lives in the present, Aware of surroundings, Notices details, Practical, Goes by senses, Factual.

Intuitive: Intuition refers to how people process data. Intuitive people focus on the future and the possibilities. They process information through patterns and impressions. They read between the lines, they are abstract thinkers. It is also an ability to deal with the information on the basis of its hidden potential and its possible existence intuitive types.

Common intuitive traits: Future-focused, Sees possibilities, Inventive, Imaginative, Deep, Abstract, Idealistic, Complicated, Theoretical.

Thinking: Thinking is an ability to deal with information on the basis of its structure and its function. Thinking refers to how people make decisions. Thinking people are objective and make decisions based on facts. They are ruled by their head instead of their heart. Thinking people judge situations and others based on logic.

Common thinking traits: Logical, Objective, Decides with head, Wants truth, Rational, Impersonal, Critical, Thick-skinned, Firm with people, Driven by thought.

Feeling: Feeling refers to how people make decisions. Feeling people are subjective and make decisions based on principles and values. They are ruled by their heart instead of their head. Feeling people judge situations and others based on feelings and extenuating circumstances. It is an ability to deal with information on the basis of its initial energetic condition and its interactions.

Common feeling traits: Decides with heart, Dislikes conflict, Passionate, Driven by emotion, Gentle, Easily hurt, Empathetic, Caring of others, Warm. 


\section{Cognitive Style of Humanities, Commerce and Science Students - A Study On Higher Secondary Students from West Bengal}

Judging: Judging is the preference outwardly displayed. Judging does not mean "judgmental”. Judging people like order, organization and think sequentially. They like to have things planned and settled. Judging people seek closure. Judging types are motivated into activity by their decisions resulting from the changes in a situation.

Common judging traits: Decisive, Controlled, Good at finishing, Organized, Structured, Scheduled, Quick at tasks, Responsible, Likes closure, Makes plans.

Perceiving: Perceiving is the preference outwardly displayed. Perceiving people are flexible, like to keep their options open and think randomly. They like to act spontaneously and are adaptable. Perceivers like to keep things open ended. Perceiving types are motivated into activity by the changes in a situation.

Common perceiving traits: Adaptable, Relaxed, Disorganized, Care-free, Spontaneous, Changes tracks midway, Keeps options open, Procrastinates, Dislikes routine, Flexible.

\section{NEED FOR THE STUDY:}

The present study was actually conducted to find out that whether there is a difference between males and females in terms of cognitive style and whether cognitive style differs along with the stream of study.

\section{Hypothesis:}

H1- There will be no effect of stream of study on cognitive style of Higher Secondary students in terms of - Introversion, Extraversion, Sensing, Intuitive, Feeling, Thinking, Judging, and Perceiving.

H2-There will be no effect of gender on cognitive style of Higher Secondary students in terms of- Introversion, Extraversion, Sensing, Intuitive, Feeling, Thinking, Judging, and Perceiving.

H3-There will be no significant effect of interaction between gender and stream of study with respect to above mentioned dimensions of cognitive style.

\section{METHOD}

\section{Sample:}

For the present investigation a sample group of 90 students (30 each from Humanities, Commerce, and Science) were selected according to the requirement of the study and convenience of data collection by the researcher.

\section{Inclusion Criteria of the Sample Group:}

AGE: $16-18$ years

GENDER: Both male and female were taken for this study.

EDUCATIONAL QUALIFICATION: Higher secondary students. 
ANY PAST HISTORY OF ILLNESS (INCLUDING BOTH PHYSICAL OR PSYCHOLOGICAL): data of the Students having any sort of physical or psychological illness were not taken into consideration.

SOCIO-ECONOMIC STATUS: middle class and above

AREA: Howrah, Hooghly and Kolkata.

\section{Tools Used:}

In conducting the present study 2 questionnaire were administered. They are:

* Background information schedule

* Cognitive style questionnaire.

\section{DESCRIPTION OF THE TOOLS:}

1. Background information schedule was developed to cover the aspects like age, gender, education, family income, number of siblings, residential locality, and overall socio economic status.

2. The Cognitive style questionnaire by Ancona, Kochan, Scully, Van Maanen, and Westney (1997) was chosen to determine the personality style of the higher secondary students of Humanities, Commerce, and Science.

This is a set of questions designed to indicating the cognitive style. The answer chosen to any question is neither "right" nor "wrong". Simply indicating the student's personality style.

Below there are a number of paired statements and words. Each one should be credited with a score that each pair adds up to 5. For example:

In describing my work, I would say it is:

a. Challenging and exciting

b. Routine and dull

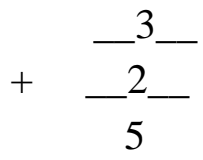

Clearly, work can sometimes be challenging and sometimes dull. In the above example it has been indicated that mostly finding work to be challenging, weighted "challenging" as 3 and "routine" as 2 . The students also have the provision to assign number to the statements as $4+1$, or $0+5$, or any other combination that adds to 5 . (Negative numbers should not be used). The scores of all the different 8 dimensions were added together. Then the mean and S.D of the scores were determined. The scoring of the dimensions is like the following way.

Extraversion $2 b+5 b+8 a+15 a+19 a+21 a+28 b$

Introversion $2 a+5 a+8 b+15 b+19 b+21 b+28 a$

Sensing $\quad 4 b+9 a+11 a+12 b+17 b+25 a+29 a+30 b$ 
Intuitive $\quad 4 a+9 b+11 b+12 a+17 a+25 b+29 b+30 a$

Thinking $\quad 1 b+7 b+13 b+16 a+22 b+24 a+26 b+27 b$

Feeling $\quad 1 a+7 a+13 a+16 b+22 a+24 b+26 a+27 a$

Judging $\quad 3 a+6 b+10 a+14 b+18 a+20 b+23 a$

Perceiving $3 b+6 b+10 a+14 a+18 b+20 a+23 b$

The Chronbach's Alpha method of Reliability was used in order to determine the extent to which each of the domains is reliable. After administering it was found out as following:

- $\quad$ The Chronbach's Alpha for the category of Extroversion was found out to be 0.539. The numbers of items present under this domain were 7.

- $\quad$ The Chronbach's Alpha for the category of Introversion was found out to be 0.530 . The numbers of items present under this domain were 7.

- $\quad$ The Chronbach's Alpha for the category of Sensing was found out to be 0.797 . The numbers of items present under this domain were 8.

- $\quad$ The Chronbach's Alpha for the category of Intuitive was found out to be 0.911 . The numbers of items present under this domain were 8 .

- $\quad$ The Chronbach's Alpha for the category of Thinking was found out to be 0.849 . The numbers of items present under this domain were 8.

- $\quad$ The Chronbach's Alpha for the category of Feeling was found out to be 0.861 . The numbers of items present under this domain were 8.

- $\quad$ The Chronbach's Alpha for the category of Judging was found out to be 0.799 . The numbers of items present under this domain were 7 .

- $\quad$ The Chronbach's Alpha for the category of Judging was found out to be 0.884 . The numbers of items present under this domain were 7.

\section{RESULTS AND DISCUSSION:}

Brief Summary of the Mean and S.D of the Variables Under Study (Cognitive Style).

\begin{tabular}{|c|c|c|c|c|c|c|}
\hline Variables & \multicolumn{2}{|c|}{ Humanities } & \multicolumn{2}{c|}{ Commerce } & \multicolumn{2}{c|}{ Science } \\
\hline & MEAN & S.D & MEAN & S.D & MEAN & S.D \\
\hline Extraversion & 17.10 & 5.70 & 16.87 & 5.08 & 16.43 & 5.72 \\
\hline Introversion & 18.70 & 5.29 & 18.13 & 5.08 & 18.57 & 5.72 \\
\hline Sensing & 20.93 & 6.99 & 23.70 & 4.25 & 24.93 & 3.32 \\
\hline Intuitive & 18.30 & 6.16 & 16.30 & 4.25 & 15.10 & 3.34 \\
\hline Thinking & 18.73 & 4.59 & 19.95 & 4.46 & 18.73 & 3.42 \\
\hline Feeling & 19.53 & 5.67 & 20.40 & 3.81 & 21.33 & 4.78 \\
\hline Judging & 19.63 & 6.35 & 14.60 & 3.81 & 13.67 & 4.78 \\
\hline Perceiving & 22.00 & 5.65 & 20.07 & 4.49 & 21.27 & 3.42 \\
\hline
\end{tabular}


Hypothesis 1 and 2 are accepted for the dimensions of Sensing, Intuition and Perceiving. For rest of the dimensions, the hypothesis is not accepted. Hypothesis 3 has been totally rejected as for none of the dimensions the interaction effect has been found to be significant.

Statistical Analysis (ANOVA)

\begin{tabular}{|c|c|c|c|c|c|c|}
\hline DIMENSION & & $\begin{array}{c}\text { TYPE III } \\
\text { SUM OF } \\
\text { SQUARES }\end{array}$ & Df & $\begin{array}{c}\text { MEAN } \\
\text { SQUARES }\end{array}$ & $\mathbf{F}$ & SIGNIFICANCE \\
\hline & STREAM & 6.867 & 2 & 3.433 & .112 & .894 \\
\hline \multirow[t]{3}{*}{ EXTRAVERSION } & GENDER & 21.511 & 1 & 21.511 & .704 & .404 \\
\hline & Stream*gender & 52.156 & 2 & 26.078 & .854 & .429 \\
\hline & STREAM & 5.267 & 2 & 2.633 & .091 & .913 \\
\hline \multirow[t]{3}{*}{ INTROVERSION } & GENDER & 19.600 & 1 & 19.600 & 675 & .414 \\
\hline & Stream*gender & 50.867 & 2 & 25.433 & .876 & .420 \\
\hline & STRFAM & 251756 & 2 & 125.878 & 5102 & 008 \\
\hline \multirow[t]{3}{*}{ SENSING } & GENDER & 108.900 & 1 & 108.900 & 4.413 & .039 \\
\hline & Stream*gender & 82.467 & 2 & 41.233 & 1.671 & .194 \\
\hline & STREAM & 156.800 & 2 & 78.400 & 3.637 & .031 \\
\hline \multirow[t]{3}{*}{ INTUITIVE } & GENDER & 84.100 & 1 & 84.100 & 3.901 & .052 \\
\hline & Stream*gender & 52.267 & 2 & 26.133 & 1.212 & 303 \\
\hline & STREAM & 57.156 & 2 & 28.578 & 1.311 & .275 \\
\hline \multirow{3}{*}{ THINKING } & GENDER & 17.778 & 1 & 17.778 & .816 & .369 \\
\hline & Stream*gender & 1.422 & 2 & .711 & .033 & .968 \\
\hline & STREAM & 30.422 & 2 & 15.211 & 847 & .432 \\
\hline \multirow[t]{3}{*}{ FEELING } & GENDER & .544 & 1 & .544 & .030 & .862 \\
\hline & Stream*gender & 21.489 & 2 & 10.744 & .598 & .552 \\
\hline & STREAM & 48.622 & 2 & 24.311 & 1.031 & .361 \\
\hline \multirow[t]{3}{*}{ JUDGING } & GENDER & 1.111 & 1 & 1.111 & .047 & .829 \\
\hline & Stream*gender & 35.822 & 2 & 17.911 & 760 & .471 \\
\hline & STREAM & 618.067 & 2 & 309.033 & 12.767 & .000 \\
\hline \multirow{2}{*}{ PERCEIVING } & GENDER & 104.544 & 1 & 104.544 & 4.319 & .041 \\
\hline & Stream*gender & 115.089 & 2 & 57.544 & 2.377 & .099 \\
\hline
\end{tabular}


Brief Summary of the Mean Scores of the Variables Under Study in Terms Of Stream And Gender of the three Different Groups (Humanities, Commerce And Science) is Presented Below.

\begin{tabular}{|c|c|c|c|c|c|c|}
\hline Variables & \multicolumn{2}{|c|}{ Humanities } & \multicolumn{2}{c|}{ Commerce } & \multicolumn{2}{c|}{ Science } \\
& Male & Female & Male & Female & Male & Female \\
\hline & Mean & Mean & Mean & Mean & Mean & Mean \\
\hline Extraversion & 16.25 & 17.93 & 15.67 & 18.07 & 17.00 & 15.87 \\
\hline Introversion & 19.47 & 17.93 & 19.33 & 16.93 & 18.00 & 19.13 \\
\hline Sensing & 23.27 & 18.60 & 24.67 & 22.73 & 24.93 & 24.93 \\
\hline Intuitive & 16.40 & 20.20 & 15.33 & 17.25 & 15.07 & 15.13 \\
\hline Thinking & 21.47 & 22.53 & 19.80 & 20.33 & 20.33 & 21.80 \\
\hline Feeling & 18.13 & 19.33 & 20.27 & 19.67 & 19.67 & 18.20 \\
\hline Judging & 19.13 & 19.93 & 21.40 & 19.40 & 19.40 & 21.60 \\
\hline Perceiving & 17.13 & 22.13 & 13.60 & 15.60 & 15.60 & 13.40 \\
\hline
\end{tabular}

From the Anova table, it has been found that in the category of Stream the between group $\mathrm{F}$ score is significant in case of Sensing, Intuition and Perceiving. In general the Science stream students have scored the highest in the dimension of sensing and the least scorer is the Humanities group of students. Again in the dimension of Intuition, the Humanities group students have scored the highest and the least score has been made by the students belonging to Science group. Finally in the dimension of Perceiving the highest scores have been made by the humanities group and the least score has been made by the students belonging to Commerce group.

It has also been found that in case of Gender the Mean scores of males in the category of Sensing are highest for the Science group followed by Commerce group and finally by Humanities group. Again the mean scores of females in the category of Sensing are highest for the Science group followed by Commerce group and finally by Humanities group. The Mean scores of males in the category of Intuition are highest for the Humanities group followed by Commerce and finally by Science group. Again the mean scores of females in the category of Intuition are highest for the Humanities group followed by Commerce group and finally by Science group.The Mean scores of males in the category of Perceiving are highest for the Humanities group followed by Science and finally by Commerce group. Again the mean scores of females in the category of Intuition are highest for the Humanities group followed by Commerce group and finally by Science group.

In case of Gender*Stream category, the scores of the interaction between gender and stream has not been found to be significant in case of any of the dimensions of cognitive style. 


\section{Cognitive Style of Humanities, Commerce and Science Students - A Study On Higher Secondary Students from West Bengal}

A study was conducted by Dr. Parkash Chandra Jena (2013) on 300 rural senior secondary school students where the finding revealed that the group difference between male and female undergraduate students on systematic cognitive style as well as on intuitive cognitive style is found to be insignificant, but in the present study the effect of Gender has been found to be significant for the following dimensions of cognitive style, namely, Sensing, Intuition and Perceiving. Albert (2004) also conducted a study of relationship between cognitive style, gender, intelligent quotient and academic achievement of high school students and recorded a low but significant correlation between cognitive style and academic achievement. Again Parikh (2004) studied the relationship of cognitive style and academic achievement of boys and girls and found that achievement was not related to cognitive style; boys and girls do not differ in their cognitive style. Dani (2004) studied scientific attitude and cognitive style of higher secondary students and found that boys and girls did not differ in their cognitive style. Suresh (2003) studied relationship of extraversion-introversion in adolescents to their adjustment and academic achievement and found that the relationship between introversion and home adjustment, introversion and total adjustment was negative in total sample. Jahan (2004) examined personality profile of students of science, arts and commerce at higher secondary level of education in relation to their academic achievement and found that the overachievers of science stream were more reserved, intelligent, emotionally stable, controlled and relaxed as compared to underachievers; the overachiever of arts stream were more warm hearted, intelligent, affected by feelings, undemonstrative, assertive, enthusiastic, conscientious, and tensed as compared to underachievers; the over achievers of commerce stream were more reserved, intelligent, affected by feelings, sober, conscientious and self-assured as compared to the underachievers. In the present study also the Science stream students have found to score highest in the dimension of Sensing, Intuition and Perceiving. In various other studies it has been found that the personality profiles and cognitive factors of academic failure among science and arts students at various levels and the relationship between different personality factors viz. intelligence, conformity, achievement motivation, study habits, memory span and academic failure were not significant. The present study reveals that the Humanities students scored highest in the Intuitive dimension.

\section{IMPLICATIONS}

* The present study helps to give a better view of the cognitive style adapted by the students which reveals the personality traits of the

Students and it will help in the determination of their professional placement in future.

* This study is quite beneficial in the field of educational psychology.

* One of the important issues was the early finding of marked individual differences among students in how they perform this task.

* Findings indicated that quality questioning, as well as activities and pedagogy that stimulate met cognition are key activities for stimulating students' cognition. 


\section{Cognitive Style of Humanities, Commerce and Science Students - A Study On Higher Secondary Students from West Bengal}

\section{REFERENCES}

Albert J. (2004). The Cognitive Style Index, A Measure Of Intuition Analysis For School Students. Behaviour And Research Therapy, 26, Page: 337-354.

Baron, R. A., (2006).Psychology. New Delhi: Prentice Hall Of India.

ÇagiltayDr.Kürat,(January 2005). Learning Strategies Of Students With Different Cognitive Style In A Hypermedia Environment Yecan, Esra M.S., Department Of Computer Education And Instructional Technology Supervisor.133 Pages.

Cano-Garcia, F. \& Hughes, E. H. (2000).Learning And Thinking Styles: An Analysis Of Their Interrelationship And Influence On Academic Achievement. Educational Psychology, 20(4), Page: 413-430.

Chen. S.Y And Liu, X. (2009). An Integrated Approach For Modelling Learning Patterns Of Students In Web-Based Instruction: A Cognitive Style Perspective. Acm Transactions On Computer-Human Interaction, 15 (1), 1-28 Pages.

Colamn Andrew M., 2009.Dictionary Of Psychology. New York: Oxford University Press.P.565

Dani, D.N. (2004). Scientific Attitude And Cognitive Style Of Higher Secondary Students, Ph.D. Education.

Ellis, R. (2000). The Study Of Second Language Acquisition. Oxford: Oup.

Grossmann Deborah,(March 2011). A Study Of Cognitive Styles And Strategy Use By Successful And Unsuccessful Adult Learners In Switzerland By- A Dissertation Submitted To The School Of Humanities Of The University Of Birmingham In Part Fulfilment of The Requirements For The Degree Of Master Of Arts.

Jahan D. (2004).Personality Profile Of Students Of Science, Arts And Commerce. Journal Of Educational Psychology, Vol.2, 67, Page: 68-203.

Jena P.C. (2013). Cognitive Style Of Rural Senior Secondary School Students In Relation To Their Gender And Stream. International Journal Of Education And Psychological Research (IJEPR) Vol-2, Issue-4, Pg: 37-44.

Kirton, M.J. Adaptation And Innovation In The Context Of Diversity And Change Routledge, London, 2003,P. 392

Parikh J. (2004). The Relation Of Rational And Experiential Information Processing Styles To Personality, Basic Believes And The Ratio Bias Problem. Journal Of Personality And Social Psychology, 76, Page: 972-987.

Rishipal (2012). Cognitive Style A Predictor Of Managerial Effectiveness: Study Of Public And Private Sector Bank Managers In India. Global Journal Of Management And Business Research. Vol - 12, Issue - 2, 20 - 26.Paripex - Indian Journal Of Research, 2(7), 55-56. Robbins, S. P., (2005).Essentials Of Educational Technology. New Delhi: Phi. Santrock, J.W.(2006).Organizational Behaviour. New Delhi: Prentice Hall Of India. (11th Ed). Suresh B. (2003). A Study Of The Relationship Of Extraversion-Introversion In Adolescents To Their Adjustment And Academic Achievement. Indian Education Today And Tomorrow, Second Edition, International Publishing House. 